\title{
A Study on the Global Scenario of COVID-19 Related Case Fatality Rate, Recovery Rate and Prevalence Rate and Its Implications for India-A Record Based Retrospective Cohort Study
}

\author{
Vinod K. Ramani' ${ }^{1}$, R. Shinduja ${ }^{2}$, K. P. Suresh ${ }^{2}$, Radheshyam Naik ${ }^{3}$ \\ ${ }^{1}$ Preventive Oncology, Healthcare Global Enterprise Ltd., Bangalore, India \\ ${ }^{2}$ Spatial Epidemiology Lab, ICAR-National Institute of Veterinary Epidemiology and Disease Informatics, Bengaluru, Karnataka \\ ${ }^{3}$ Medical Oncology, Healthcare Global Enterprise Ltd., Bangalore, India \\ Email: drvinod.r@hcgel.com, shindu.bioteck@gmail.com, sureshkp97@gmail.com, radheshyam_n@yahoo.com
}

How to cite this paper: Ramani, V.K., Shinduja, R., Suresh, K.P. and Naik, R. (2020) A Study on the Global Scenario of COVID-19 Related Case Fatality Rate, Recovery Rate and Prevalence Rate and Its Implications for India-A Record Based Retrospective Cohort Study. Advances in Infectious Diseases, 10, 233-248.

https://doi.org/10.4236/aid.2020.103023

Received: October 13, 2020

Accepted: November 21, 2020

Published: November 24, 2020

Copyright $\odot 2020$ by author(s) and Scientific Research Publishing Inc. This work is licensed under the Creative Commons Attribution International License (CC BY 4.0).

http://creativecommons.org/licenses/by/4.0/

\begin{abstract}
Importance: Corona virus disease 2019 (COVID-19) caused by the severe acute respiratory syndrome coronavirus 2 (SARS-CoV-2) is the pandemic claiming millions of lives since the first outbreak was reported in Wuhan, China during December 2019. It is thus important to make cross-country comparison of the relevant rates and understand the socio-demographic risk factors. Methods: This is a record based retrospective cohort study. Table 1 was extracted from https://www.worldometers.info/coronavirus/ and from the Corona virus resource center (Table 2, Figures 1-3), Johns Hopkins University. Data for Table 1 includes all countries which reported $>1000$ cases and Table 2 includes 20 countries reporting the largest number of deaths. The estimation of CFR, RR and PR of the infection, and disease pattern across geographical clusters in the world is presented. Results: From Table 1, we could infer that as on $4^{\text {th }}$ May 2020, COVID-19 has rapidly spread world-wide with total infections of $3,566,423$ and mortality of 248,291 . The maximum morbidity is in USA with 1,188,122 cases and 68,598 deaths (CFR 5.77\%, RR 15\% and PR $16.51 \%$ ), while Spain is at the second position with 247,122 cases and 25,264 deaths (CFR 13.71\%, RR 38.75\%, PR 9.78\%). Table 2 depicts the scenario as on $8^{\text {th }}$ October 2020 , where-in the highest number of confirmed cases occurred in US followed by India and Brazil (cases per million population: 23,080, $5007 \& 23,872$ respectively). For deaths per million population: US recorded 647, while India and Brazil recorded 77 and 708 respectively. Conclusion: Studying the distribution of relevant rates across different geographi-
\end{abstract}


cal clusters plays a major role for measuring the disease burden, which in-turn enables implementation of appropriate public healthcare measures.

\section{Keywords}

Case Fatality Rate, COVID-19, Prevalence Rate, Recovery Rate, Statistical Analysis

\section{Introduction}

The present study concentrates on the current outbreak of the novel Corona virus disease 2019 (COVID-19) which originated in Wuhan, Hubei province, China, first reported during December 2019. The contagious severe acute respiratory syndrome corona virus 2 (SARS-CoV-2) has subsequently spread to European and American countries, causing widespread morbidity and mortality. On $30^{\text {th }}$ January 2020, WHO defined the outbreak as a Public health emergency of International concern [1]. WHO's Situation Report-106 released on $5^{\text {th }}$ May 20 on the novel Corona virus (2019-nCoV), states that globally there are 3,517,345 confirmed cases and 243,401 deaths [2]. WHO declared COVID-19 as a pandemic on March 11, 2020 [3], and advised Governments to take urgent and aggressive action. So far, the pandemic has affected 210 countries across 6 continents [4].

The prevalence and incidence of a disease are among the most fundamental measures in epidemiology, which measure the burden of disease in a given population represented as the number of people affected [5]. Therefore, it is essential to know the counts of the number of people affected with a disease to plan for the health care needs.

2019-nCoV is spread via cough or respiratory droplets, contact with body fluids and from contaminated surfaces. Non-symptomatic individuals can also effectively transmit the infection, and face masks cannot limit the virus tropism to non-respiratory mucosal surfaces. Patients in remission can also transmit the virus. The mortality rate of novel corona virus could be between that of seasonal influenza and SARS (Severe acute respiratory syndrome).

$\mathrm{R}_{0}$ or the basic reproduction number is the average number of cases in a susceptible population generated by one infected individual [6]. Human-to-human transmission of 2019-nCoV is confirmed with $\mathrm{R}_{0}$ of $1.4-2.5$. Incubation period is estimated between 2 to 10 days. Reports suggest that elderly and those with co-morbidities are at greatest risk of death. Acute respiratory distress syndrome is the likely cause of death. The biological cytokine storm in an individual is linked with the severity of the disease. There is no specific vaccine or anti-viral drug against this virus. Neither has the natural animal host been identified nor the presence of any intermediate host. However, 2019-nCoV is found to closely resemble the virus found in Chinese horseshoe bats [7].

Human pathogenic corona viruses (SARS-CoV) and SARS-CoV-2 bind to the epithelial cells of various organs through the protein receptor: angiotensin-con- 
verting enzyme 2 (ACE2). This is expressed on the target cells of the lung, intestine, kidney and blood vessels. However, in patients with hypertension and diabetes who are most often treated with ACE inhibitors or angiotensin II type-1 receptor blockers (ARBs), the expression of ACE2 is increased substantially. Even ibuprofen and thiazolidinediones can increase ACE2. This in-turn would facilitate COVID-19 infection. Increased expression of ACE2 is also found among the elderly age group. Among the Asian population, ACE2 polymorphisms have been linked with hypertension, diabetes mellitus and stroke. This could genetically predispose such individuals for SARS-CoV-2 infection. Hypertensives need to be substituted with calcium channel blockers which do not increase the expression of ACE2. Suitable alternative treatment needs to be initiated for diabetics and stroke patients [8].

The high prevalence of COVID-19 infection among asian men when compared with women, and patients of other ethnicities could be due to their predominant expression of ACE2. This sex predisposition might be associated with much higher smoking rate in men than in women [9]. Other literature does not support the evidence for an association between smoking and prevalence or severity of COVID-19.

This study focused on computing the Case Fatality Rate (CFR), Recovery Rate (RR) and Prevalence Rate (PR) of COVID-19 infections across the geographical clusters. Prevalence is used to compare disease burden across locations or time periods, and provides the foundation for public policy which enables implementing appropriate healthcare measures.

Objectives: 1) To analyze the computed case fatality rate (CFR), recovery rate (RR) and prevalence rate (PR) of the infection for countries,

2) To draw inference of our findings for the population of India.

\section{Methods}

The data for the initial part of the study was extracted from

https://www.worldometers.info/coronavirus/ owned by the data company "Dadax" [10]. This database includes 85 countries reporting $>1000$ COVID-19 cases as on $4^{\text {th }}$ May 2020 [10].

This record based retrospective cohort study includes all countries which reported $>1000$ cases during the current COVID-19 pandemic. Measures such as total number of cases, total reported deaths, total recovered patients and total number of patients tested were extracted from the database and tabulated. Period prevalence provides a better measure since it includes all cases during a particular time period [11]. In our study, period prevalence has been computed from December 2019 till $4^{\text {th }}$ May 2020. To calculate PR, CFR and RR in Table 1, we have categorised the study based on the six continents viz., Asia, Africa, Europe, North America, Oceania and South America.

Data as of October $8^{\text {th }} 20$, for the second part of the study (Table 2, Figures 1-3) were derived from the Corona virus resource center, Johns Hopkins University of Medicine, USA [12]. 
The prevalence, mortality and recovery rate of individual countries were thus calculated:

As per the Dictionary of Epidemiology [13],

1) Mortality rate: estimate of the portion of a population that dies during a specified period,

2) Case fatality rate (CFR): the proportion of cases of a specified condition that are fatal within a specified time,

3) Prevalence rate: the proportion of the population that has health condition at a point in time,

4) Cumulative death rate [14]: the proportion of a group that dies over a specified time,

5) Recovery rate (RR) [15] from COVID-19: (No. of recovered cases/No. of closed cases) $\times 100$,

6) Case fatality ratio (\%): Number of recorded deaths/Number of cases $\times 100$.

The denominator for computing the PR in our study is essentially not the population at risk, but the total number of individuals tested for $2019-\mathrm{nCoV}$. The numerator includes individuals who tested positive for this virus. Hence, ideally it is "Prevalence proportion".

\section{Results}

Data from Table 1 depicts the initial stages of the epidemic, where-in the high CFR (>10\%) in certain countries (Italy, Spain, France, UK, Belgium) could be due to poor social distancing measures along with co-morbid conditions among patients. The high CFR in Italy could also be explained by the fact that $23 \%$ of their population were $>65$ years old [16], and COVID-19 is more lethal in older patients. The denominator for computing CFR used in Italy and Spain is quantitatively less, as it includes screened individuals requiring hospital admission only [17]. In countries such as South Korea and Switzerland, massive screening measures have been implemented and the reported case fatality rate is $<1 \%$ [18]. The denominator in this scenario may include many mild or asymptomatic cases. Differences in the definition of a COVID-19 related death could also explain the variation in CFR among different countries.

In Table 1, PR is not computed for China as information regarding the number of tests is not available. This could contribute to the high RR of $93.83 \%$ in China and could also be due to a milder strain of infection, and an equipped healthcare system enabling positive patients to effectively recover from the infection.

Table 2 sourced from daily Dashboard of the Center for Systems Science and Engineering (CSSE) [12], Johns Hopkins University of Medicine, USA, depicts the current morbidity of the COVID-19 pandemic for 30 countries reporting the highest case counts. The COVID-19 daily dashboard, confirmed cases: $36,234,307$, deaths: 1,057,043 (2.9\%) and recoveries: 25,276,017 (69.8\%).

During an epidemic, cases could be defined as total cases (every confirmed case) or closed cases (recovered or died). In the initial phase of an epidemic, 
Table 1. Shows the continent-wise distribution of COVID-19 CFR, RR and PR.

\begin{tabular}{|c|c|c|c|c|c|c|c|}
\hline Country & $\begin{array}{l}\text { Total } \\
\text { Cases }\end{array}$ & $\begin{array}{c}\text { Total } \\
\text { Deaths }\end{array}$ & $\begin{array}{c}\text { Total } \\
\text { Recovered }\end{array}$ & Total Tests & $\begin{array}{c}\text { Case Fatality } \\
\text { Rate (\%) }\end{array}$ & $\begin{array}{l}\text { Recovery } \\
\text { Rate (\%) }\end{array}$ & $\begin{array}{c}\text { Prevalence } \\
\text { Rate (\%) }\end{array}$ \\
\hline \multicolumn{8}{|l|}{ Asia } \\
\hline Turkey & 126,045 & 3397 & 63,151 & $1,135,367$ & 2.70 & 50.10 & 11.10 \\
\hline Iran & 97,424 & 6203 & 78,422 & 496,273 & 6.37 & 80.50 & 19.63 \\
\hline China & 82,880 & 4633 & 77,766 & N/A & 5.59 & 93.83 & N/A \\
\hline India & 42,533 & 1391 & 11,775 & $1,107,233$ & 3.27 & 27.68 & 3.84 \\
\hline Saudi Arabia & 27,011 & 184 & 4134 & 352,555 & 0.68 & 15.30 & 7.66 \\
\hline Pakistan & 20,186 & 462 & 5590 & 212,511 & 2.29 & 27.69 & 9.50 \\
\hline Singapore & 18,205 & 18 & 1408 & 143,919 & 0.10 & 7.73 & 12.65 \\
\hline Israel & 16,208 & 232 & 9749 & 397,046 & 1.43 & 60.15 & 4.08 \\
\hline Qatar & 15,551 & 12 & 1664 & 104,435 & 0.08 & 10.70 & 14.89 \\
\hline Japan & 14,877 & 487 & 3981 & 183,251 & 3.27 & 26.76 & 8.12 \\
\hline UAE & 14,163 & 126 & 2763 & $1,200,000$ & 0.89 & 19.51 & 1.18 \\
\hline Indonesia & 11,192 & 845 & 1876 & 112,965 & 7.55 & 16.76 & 9.91 \\
\hline S. Korea & 10,801 & 252 & 9217 & 633,921 & 2.33 & 85.33 & 1.70 \\
\hline Bangladesh & 9455 & 177 & 1063 & 81,434 & 1.87 & 11.24 & 11.61 \\
\hline Philippines & 9223 & 607 & 1214 & 120,736 & 6.58 & 13.16 & 7.64 \\
\hline Malaysia & 6298 & 105 & 4413 & 195,833 & 1.67 & 70.07 & 3.22 \\
\hline Kuwait & 4983 & 38 & 1776 & 196,397 & 0.76 & 35.64 & 2.54 \\
\hline Kazakhstan & 3920 & 27 & 1084 & 296,136 & 0.69 & 27.65 & 1.32 \\
\hline Bahrain & 3383 & 8 & 1718 & 144,155 & 0.24 & 50.78 & 2.35 \\
\hline Thailand & 2969 & 54 & 2739 & 178,083 & 1.82 & 92.25 & 1.67 \\
\hline Afghanistan & 2704 & 85 & 345 & 11,068 & 3.14 & 12.76 & 24.43 \\
\hline Oman & 2568 & 12 & 750 & 40,459 & 0.47 & 29.21 & 6.35 \\
\hline Armenia & 2386 & 35 & 1035 & 24,177 & 1.47 & 43.38 & 9.87 \\
\hline Iraq & 2296 & 97 & 1490 & 103,262 & 4.22 & 64.90 & 2.22 \\
\hline Uzbekistan & 2149 & 10 & 1319 & 242,536 & 0.47 & 61.38 & 0.89 \\
\hline Azerbaijan & 1932 & 25 & 1441 & 157,932 & 1.29 & 74.59 & 1.22 \\
\hline Sum: & 551,342 & 19,522 & 291,883 & Average: & 2.28 & 44.21 & 6.93 \\
\hline \multicolumn{8}{|l|}{ Europe } \\
\hline Spain & 247,122 & 25,264 & 148,558 & $1,932,455$ & 10.22 & 60.12 & 12.79 \\
\hline Italy & 210,717 & 28,884 & 81,654 & $2,153,772$ & 13.71 & 38.75 & 9.78 \\
\hline UK & 186,599 & 28,446 & N/A & $1,206,405$ & 15.24 & N/A & 15.47 \\
\hline France & 168,693 & 24,895 & 50,784 & $1,100,228$ & 14.76 & 30.10 & 15.33 \\
\hline Germany & 165,664 & 6866 & 130,600 & $2,547,052$ & 4.14 & 78.83 & 6.50 \\
\hline
\end{tabular}


Continued

\begin{tabular}{|c|c|c|c|c|c|c|c|}
\hline Russia & 134,687 & 1280 & 16,639 & $4,100,000$ & 0.95 & 12.35 & 3.29 \\
\hline Belgium & 49,906 & 7844 & 12,309 & 423,971 & 15.72 & 24.66 & 11.77 \\
\hline Netherlands & 40,571 & 5056 & N/A & 225,899 & 12.46 & N/A & 17.96 \\
\hline Switzerland & 29,905 & 1762 & 24,500 & 280,220 & 5.89 & 81.93 & 10.67 \\
\hline Portugal & 25,282 & 1043 & 1689 & 426,836 & 4.13 & 6.68 & 5.92 \\
\hline Sweden & 22,317 & 2679 & 1005 & 119,500 & 12.00 & 4.50 & 18.68 \\
\hline Ireland & 21,506 & 1303 & 13,386 & 169,377 & 6.06 & 62.24 & 12.70 \\
\hline Belarus & 16,705 & 99 & 3196 & 204,239 & 0.59 & 19.13 & 8.18 \\
\hline Austria & 15,597 & 598 & 13,228 & 274,355 & 3.83 & 84.81 & 5.68 \\
\hline Poland & 13,693 & 678 & 3945 & 375,948 & 4.95 & 28.81 & 3.64 \\
\hline Romania & 13,163 & 790 & 4869 & 195,508 & 6.00 & 36.99 & 6.73 \\
\hline Ukraine & 11,913 & 288 & 1548 & 129,723 & 2.42 & 12.99 & 9.18 \\
\hline Denmark & 9523 & 484 & 6987 & 233,799 & 5.08 & 73.37 & 4.07 \\
\hline Serbia & 9464 & 193 & 1551 & 101,911 & 2.04 & 16.39 & 9.29 \\
\hline Norway & 7847 & 211 & 32 & 172,586 & 2.69 & 0.41 & 4.55 \\
\hline Czechia & 7781 & 248 & 3587 & 257,678 & 3.19 & 46.10 & 3.02 \\
\hline Finland & 5254 & 230 & 3000 & 102,300 & 4.38 & 57.10 & 5.14 \\
\hline Moldova & 4121 & 125 & 1382 & 20,447 & 3.03 & 33.54 & 20.15 \\
\hline Luxembourg & 3824 & 96 & 3379 & 48,118 & 2.51 & 88.36 & 7.95 \\
\hline Hungary & 2998 & 340 & 629 & 82,010 & 11.34 & 20.98 & 3.66 \\
\hline Greece & 2626 & 144 & 1374 & 79,332 & 5.48 & 52.32 & 3.31 \\
\hline Croatia & 2096 & 79 & 1489 & 38,084 & 3.77 & 71.04 & 5.50 \\
\hline $\begin{array}{l}\text { Bosnia and } \\
\text { Herzegovina }\end{array}$ & 1857 & 77 & 825 & 33,928 & 4.15 & 44.43 & 5.47 \\
\hline Iceland & 1799 & 10 & 1717 & 50,406 & 0.56 & 95.44 & 3.57 \\
\hline Estonia & 1700 & 55 & 259 & 55,206 & 3.24 & 15.24 & 3.08 \\
\hline Bulgaria & 1618 & 73 & 308 & 47,636 & 4.51 & 19.04 & 3.40 \\
\hline North Macedonia & 1511 & 84 & 945 & 17,246 & 5.56 & 62.54 & 8.76 \\
\hline Slovenia & 1439 & 96 & 241 & 55,520 & 6.67 & 16.75 & 2.59 \\
\hline Lithuania & 1410 & 46 & 635 & 141,678 & 3.26 & 45.04 & 1.00 \\
\hline Slovakia & 1408 & 24 & 619 & 96,220 & 1.70 & 43.96 & 1.46 \\
\hline Sum: & $1,442,316$ & 140,390 & 536,869 & Average: & 5.89 & 41.97 & 7.72 \\
\hline \multicolumn{8}{|l|}{ North America } \\
\hline USA & $1,188,122$ & 68,598 & 178,263 & $7,196,740$ & 5.77 & 15.00 & 16.51 \\
\hline Canada & 59,474 & 3682 & 24,908 & 897,444 & 6.19 & 41.88 & 6.63 \\
\hline Mexico & 23,471 & 2154 & 13,447 & 93,791 & 9.18 & 57.29 & 25.02 \\
\hline Dominican Republic & 7954 & 333 & 1606 & 30,102 & 4.19 & 20.19 & 26.42 \\
\hline Panama & 7197 & 200 & 641 & 34,459 & 2.78 & 8.91 & 20.89 \\
\hline
\end{tabular}


Continued

\begin{tabular}{|c|c|c|c|c|c|c|c|}
\hline Cuba & 1649 & 67 & 827 & 53,545 & 4.06 & 50.15 & 3.08 \\
\hline Honduras & 1055 & 82 & 118 & 4810 & 7.77 & 11.18 & 21.93 \\
\hline Sum: & $1,288,922$ & 75,116 & 219,810 & Average: & 5.71 & 29.23 & 17.21 \\
\hline \multicolumn{8}{|l|}{ South America } \\
\hline Brazil & 101,826 & 7051 & 42,991 & 339,552 & 6.92 & 42.22 & 29.99 \\
\hline Peru & 45,928 & 1286 & 13,550 & 375,096 & 2.80 & 29.50 & 12.24 \\
\hline Ecuador & 29,538 & 1564 & 3300 & 78,659 & 5.29 & 11.17 & 37.55 \\
\hline Chile & 19,663 & 260 & 10,041 & 206,218 & 1.32 & 51.07 & 9.54 \\
\hline Colombia & 7668 & 340 & 1722 & 114,602 & 4.43 & 22.46 & 6.69 \\
\hline Argentina & 4783 & 246 & 1354 & 65,813 & 5.14 & 28.31 & 7.27 \\
\hline Bolivia & 1594 & 76 & 166 & 7651 & 4.77 & 10.41 & 20.83 \\
\hline Sum: & 211,000 & 10,823 & 73,124 & Average: & 4.38 & 27.88 & 17.73 \\
\hline \multicolumn{8}{|l|}{ Africa } \\
\hline South Africa & 6783 & 131 & 2549 & 245,747 & 1.93 & 37.58 & 2.76 \\
\hline Algeria & 4474 & 463 & 1936 & 6500 & 10.35 & 43.27 & 68.83 \\
\hline Egypt & 6465 & 429 & 1562 & 90,000 & 6.64 & 24.16 & 7.18 \\
\hline Morocco & 4903 & 174 & 1438 & 42,112 & 3.55 & 29.33 & 11.64 \\
\hline Cameroon & 2077 & 64 & 953 & N/A & 3.08 & 45.88 & N/A \\
\hline Djibouti & 1112 & 2 & 686 & 13,856 & 0.18 & 61.69 & 8.03 \\
\hline Ivory Coast & 1398 & 17 & 653 & 10,778 & 1.22 & 46.71 & 12.97 \\
\hline Sum: & 27,212 & 1280 & 9777 & Average: & 3.85 & 41.23 & 18.57 \\
\hline \multicolumn{8}{|l|}{ Oceania } \\
\hline Australia & 6822 & 95 & 5849 & 633,107 & 1.39 & 85.74 & 1.08 \\
\hline New Zealand & 1487 & 20 & 1276 & 152,696 & 1.34 & 85.81 & 0.97 \\
\hline Sum: & 8309 & 115 & 7125 & Average: & 1.37 & 85.77 & 1.03 \\
\hline
\end{tabular}

N/A: indicates data not available.

Table 2. List of 30 Countries with high case counts as of $8^{\text {th }}$ October 20.

\begin{tabular}{cccccc}
\hline Country & $\begin{array}{c}\text { Total } \\
\text { confirmed } \\
\text { cases }\end{array}$ & $\begin{array}{c}\text { Total } \\
\text { deaths }\end{array}$ & $\begin{array}{c}\text { Total } \\
\text { recovered }\end{array}$ & $\begin{array}{c}\text { Confirmed cases } \\
\text { per million } \\
\text { population }\end{array}$ & $\begin{array}{c}\text { Deaths per } \\
\text { million } \\
\text { population }\end{array}$ \\
\hline US & $7,554,434$ & 211,905 & $2,999,895$ & 23,080 & 647 \\
India & $6,835,655$ & 105,526 & $5,827,704$ & 5007 & 77 \\
Brazil & $5,000,694$ & 148,228 & $4,457,172$ & 23,872 & 708 \\
Russia & $1,253,603$ & 21,939 & 998,197 & 8605 & 151 \\
Colombia & 877,684 & 27,180 & 773,973 & 17,676 & 547 \\
Argentina & 840,915 & 22,226 & 670,725 & 18,898 & 500 \\
Spain & 835,901 & 32,562 & 150,376 & 17,890 & 697 \\
\hline
\end{tabular}


Continued

\begin{tabular}{|c|c|c|c|c|c|}
\hline Peru & 835,662 & 33,009 & 723,606 & 26,048 & 1029 \\
\hline Mexico & 799,188 & 82,726 & 679,693 & 6334 & 656 \\
\hline France & 693,603 & 32,463 & 102,061 & 10,354 & 485 \\
\hline South Africa & 685,155 & 17,248 & 618,127 & 11,858 & 298 \\
\hline United Kingdom & 546,959 & 42,605 & 2435 & 8227 & 641 \\
\hline Iran & 488,236 & 27,888 & 399,300 & 5919 & 338 \\
\hline Chile & 474,440 & 13,090 & 447,053 & 25,331 & 699 \\
\hline Iraq & 394,566 & 9683 & 323,815 & 10,183 & 250 \\
\hline Bangladesh & 374,592 & 5460 & 288,316 & 2312 & 34 \\
\hline Saudi Arabia & 338,132 & 4972 & 323,769 & 9983 & 147 \\
\hline Italy & 333,940 & 36,061 & 235,303 & 5526 & 597 \\
\hline Philippines & 331,869 & 6069 & 274,318 & 3040 & 56 \\
\hline Turkey & 329,138 & 8609 & 288,954 & 3999 & 105 \\
\hline Indonesia & 320,564 & 11,580 & 244,060 & 1188 & 43 \\
\hline Pakistan & 316,934 & 6544 & 302,375 & 1492 & 31 \\
\hline Germany & 312,956 & 9583 & 269,771 & 3772 & 116 \\
\hline Israel & 283,532 & 1846 & 220,046 & 31,533 & 205 \\
\hline Ukraine & 251,243 & 4807 & 112,365 & 5514 & 106 \\
\hline Canada & 175,610 & 9594 & 148,105 & 4739 & 259 \\
\hline Netherlands & 161,287 & 6587 & 4607 & 9341 & 382 \\
\hline Romania & 145,700 & 5247 & 113,112 & 7420 & 267 \\
\hline Ecuador & 143,531 & 11,743 & 120,511 & 8402 & 687 \\
\hline Morocco & 140,024 & 2439 & 118,142 & 3887 & 68 \\
\hline
\end{tabular}

Reference: https://coronavirus.jhu.edu/map.html. Source: Johns Hopkins University CSSE.

since the number of closed cases is relatively small, the CFR thus calculated is an over estimate. By contrast, when CFR is calculated for total cases it becomes an underestimate (as the numerator is underestimated) [14]. There is a time-lag associated with diagnosing and reporting cases. CFR calculated per total cases is least affected by the reporting biases. Although CFR per total cases underestimates the figure in the initial phase of outbreak, it remains the best tool to express the fatality of the disease [14].

Figure 1 [12] shows the number of deaths per 100 confirmed cases (observed case-fatality ratio). Countries at the top of this figure have the most number of deaths proportional to their COVID-19 cases, not necessarily the most deaths overall. Differences in mortality numbers can be caused due to the difference in number of people tested, demography of the population (age distribution), characteristics of the healthcare system and other unknown factors.

Figure 2 [12] plots the daily confirmed new cases (7-day moving average). Flattening the curve means the number of new COVID-19 cases has reduced when 
compared with the count of previous day. The flattened curve in the plot will show a downward trend in the number of daily new cases. This analysis using a 7-day moving average prevents skewing of data, which could happen as a result of change in reporting methods. This is calculated by averaging the values of that day, two days before and the next two days.

Figure 3 [12] charts the day-to-day outbreak in 20 Countries (with highest

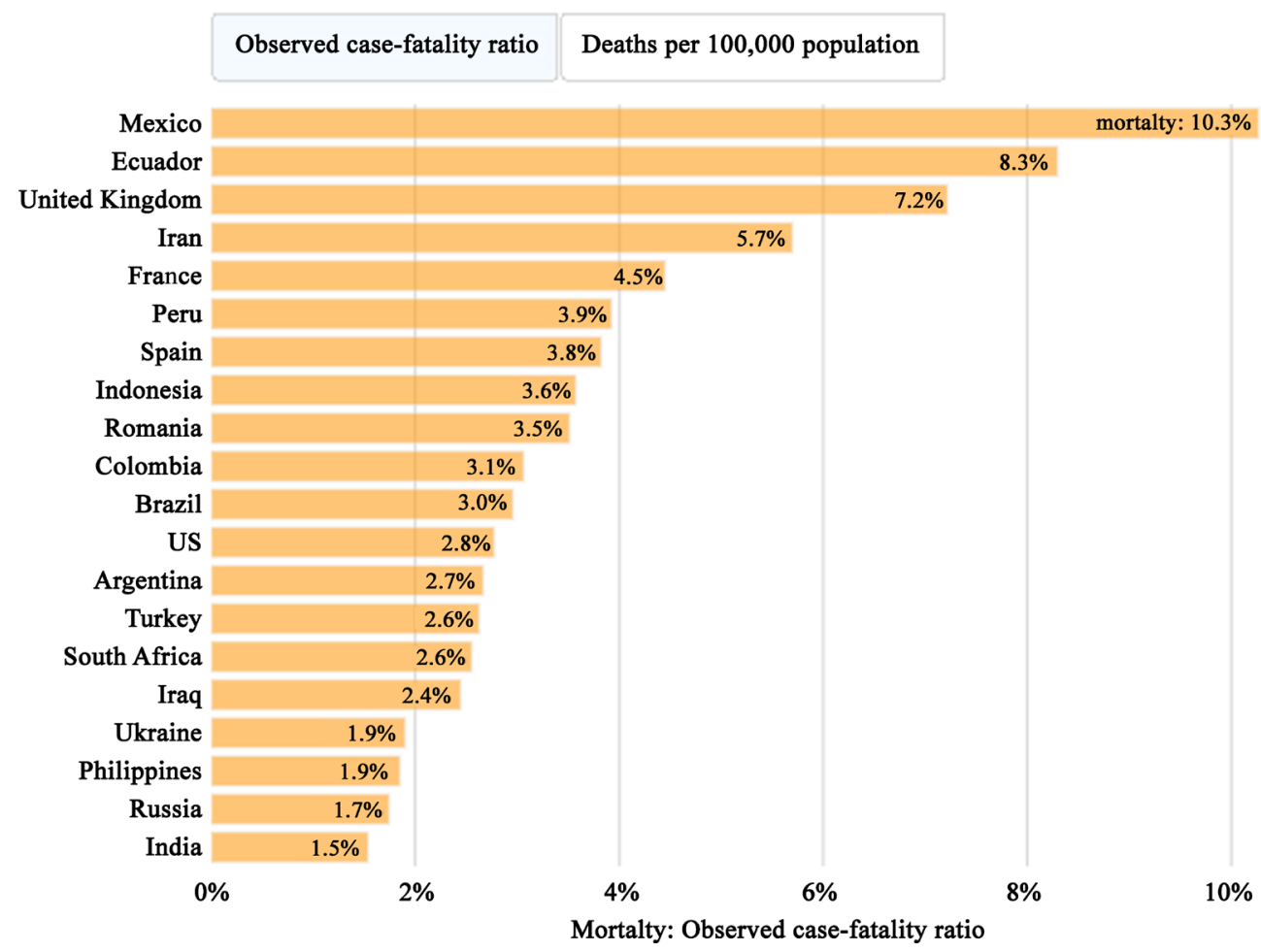

Figure 1. Case Fatality Rate of COVID-19 in infected countries. (X axis: Case fatality ratio; Y axis: Country).

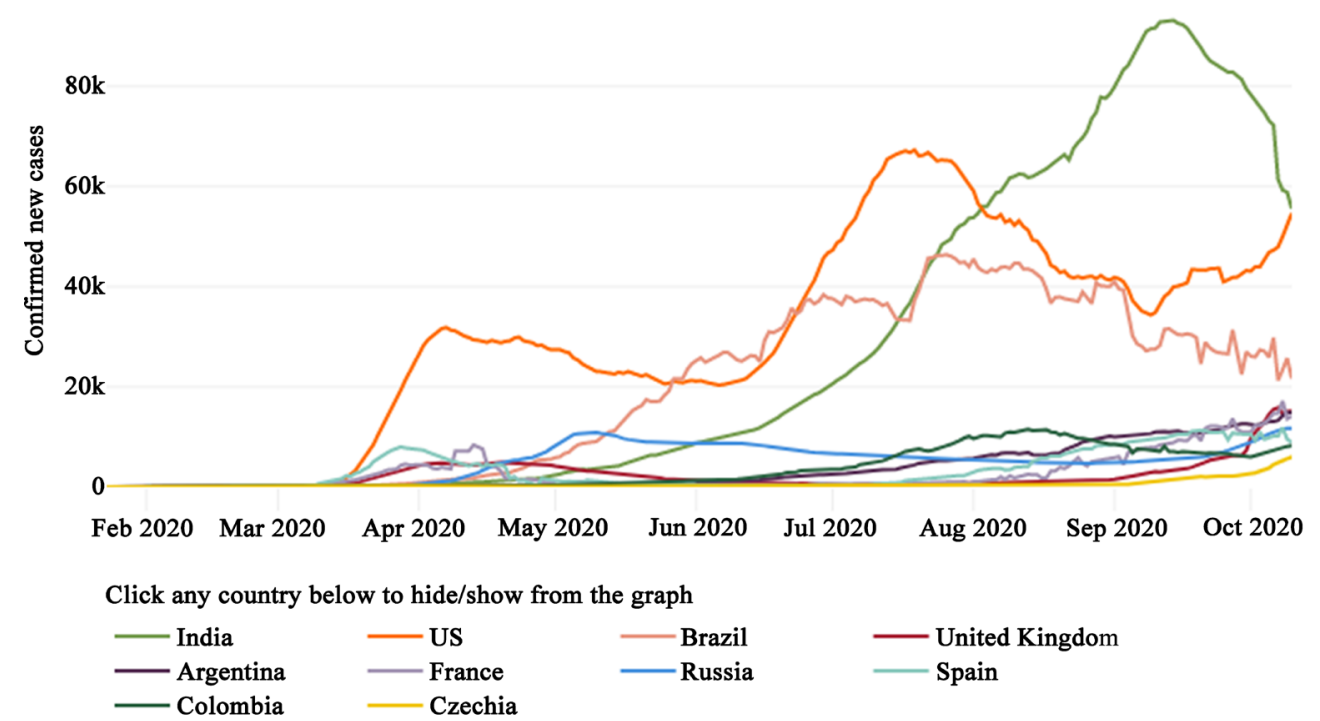

Figure 2. Outbreak evolution for the current 10 most affected countries. (X axis: Month and Year; $\mathrm{Y}$ axis: Confirmed new cases in thousands). 


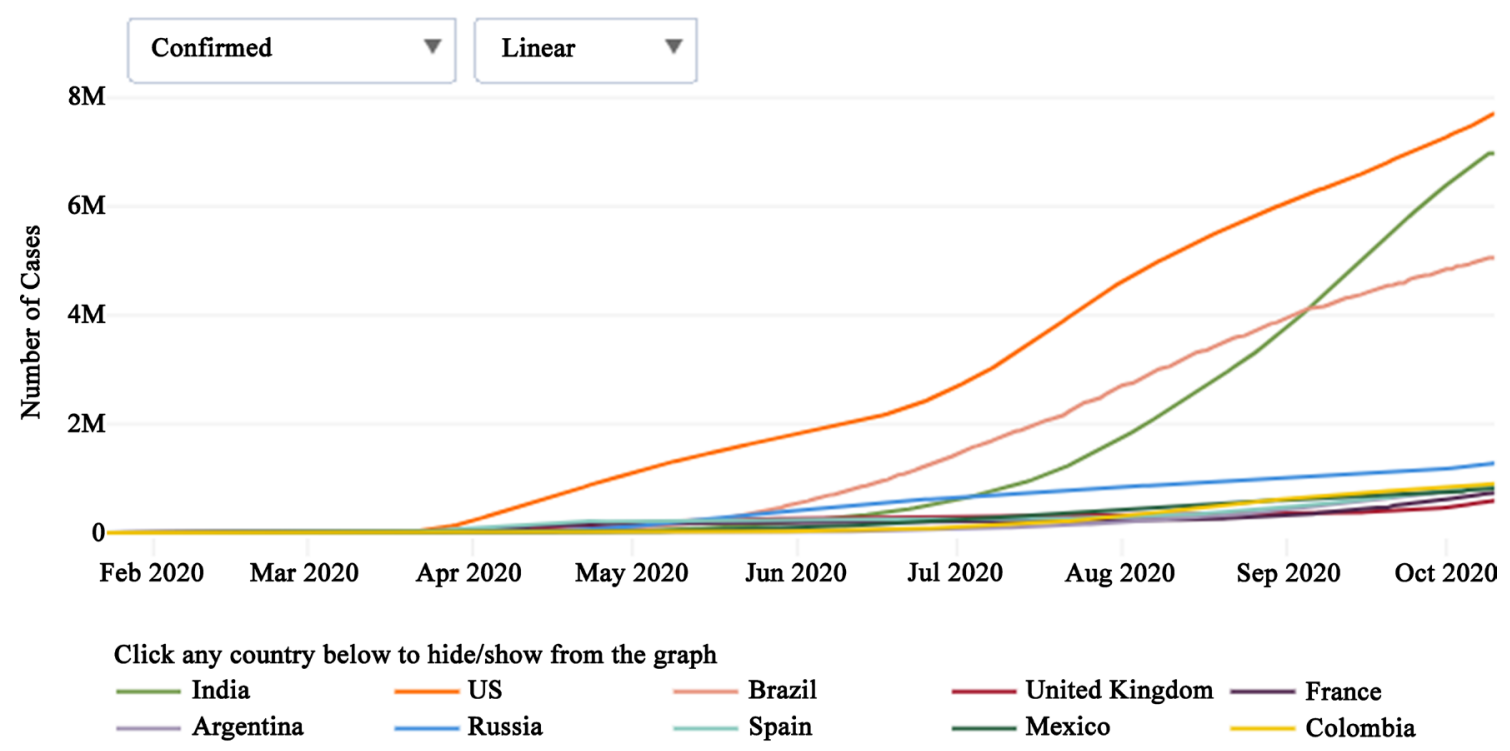

Figure 3. Day-to-day outbreak in 20 Countries. (X axis: Month and Year; Y axis: Number of cases in millions).

absolute daily number of deaths), for visualizing the succession of events. The trend lines follow the total number of cases over time, on a country-by-country basis and illustrate how the pandemic is expanding. This includes the number of people who have ever tested positive for corona virus in a given Country. An upward bend in the curve indicates either a time of explosive growth of cases or a change in how cases are defined or counted.

In India, we have low test positivity rate (ratio of positives to total persons tested: TPR), low testing rate (ratio of total persons tested to the total population) and low prevalence (number of COVID-19 cases per million population at risk). Low testing does not account for the low prevalence of COVID-19. As on $24^{\text {th }}$ Apr 20, the TPR was 4.76, which means for every 21 persons tested in India, 1 person was found infected. The epidemic has past its peak in South Korea, where the TPR has stabilized to $\sim 2 \%$. To reach this situation, South Korea has tested $1.2 \%$ of its population. Until the cut-off date of $24^{\text {th }}$ Apr 20, 525,667 persons were tested in India which needs further testing of 15.71 million persons (to reach $1.2 \%$ mark) [19].

\section{Discussion}

Using country-level data, our study aims to analyze the PR, CFR \& RR of different countries during the on-going COVID-19 pandemic. Such comparisons enable assessing the indicators of disease characteristics and recognizing the performance of health systems. Undetected cases or delayed case reporting can significantly impact these indicators, which mandates for limiting their denominator from open cases to closed cases (outcome is recovered/discharged or dead).

CFR although has a significant role in epidemiology, tends to provide crude information with regard to the current COVID-19 epidemic. It is a measure of disease severity and is often used for predicting disease course or outcome [20]. 
While estimating the CFR from country-level data, we need to factor the delay between reporting of COVID-19 cases and related deaths from the country. This could be compounded by the under-reporting of deaths.

Screening and diagnosis is by RT-PCR and rapid antigen test (RAT) in India, with antibody testing used for epidemiological purpose only. While computing the test positivity rate, some Countries report the percentage of people who test positive, some report the percentage of tests that come back positive and some report the percentage of tests that were performed on first-time recipients who indeed had COVID-19 (people over people, people over tests or tests over tests).

During the peak of the epidemic in South Korea during March 2020, 10,000 tests were conducted daily by simultaneously involving the private sector. These tests identified the infected individuals, who were later isolated and treated to break the chain of transmission. Along with other control measures, the epidemic situation was brought under control. Death rate in South Korea is $<1 \%$ when compared to $3.7 \%$ globally. In contrast, it is reported that the US Government failed to provide testing facility at multiple points. It initially did not accept the WHO approved tests, the nucleic acid testing kits sent to individual States did not test the specific genes, and the private sector was not involved in testing for infection. Death rate in US is $2.4 \%$, with many undiagnosed infections due to shortage of test kits. Before discharging a confirmed COVID-19 patient, hospital authorities need to wait for two negative results (24 hours apart). However, after the first week of infection, the nasopharyngeal swab may not provide adequate yield as the virus would have travelled lower along the respiratory tract. Testing criteria during the initial stages of the pandemic include those with respiratory symptoms and pertinent travel history, and close contacts of lab confirmed cases. Such criteria should accommodate the clinical discretion of healthcare Providers for testing their patients. Surrogate testing of samples from other influenza like illness for COVID-19, will enable understanding the unknown chains of transmission [21].

The exotic nature of this disease explains the reason for a few countries not reporting any cases of COVID-19, as no infected individual might have entered them. True prevalence of COVID-19 cases in India remains unknown, as we lack in extensive testing for SARS-CoV-2. To study the spread of COVID-19 initially, ICMR has tested for SARS-CoV-2 in samples from patients admitted with severe acute respiratory illness (SARI) in multiple centres across India during the period $15^{\text {th }}$ Feb 20 to $2^{\text {nd }}$ Apr 20 [22]. Such sentinel surveillance activities could yield false negatives. Hence the nucleic acid amplification test: real time reverse transcriptase polymerase chain reaction (RT-PCR) should be supplemented with antibody testing. In India, E (envelope protein) and RdRp (RNA dependent RNA polymerase) genes of SARS-CoV-2 were tested in the RT-PCR technique.

During the initial stages, UK paid the price for strategizing herd immunity as a policy and exposing the population. Dr. Peravali [23] clarifies that herd immunity could be used as a strategy only if the mortality rate is in the range of $1 \%$ - 
$2 \%$. Dr. Muliyil [23] clarifies that $60 \%$ of the population should have developed immunity against the virus for the onset of herd immunity. Presently on account of unknown modes of transmission, the focus should shift from not just isolating infected individuals but towards protecting the vulnerable individuals as well as responsible self-quarantine of contacts. Contact tracing involves locating all contacts of a positive patient, listing them and regularly following up on the specific symptoms and testing for infection. It can prevent transmission in both containment (breaking all chains of transmission) and mitigation (flatten the curve) phases of the pandemic response.

In COVID-19, the main cause of death is recognized to be respiratory failure and subsequent hypoxaemia. This needs to be supported by invasive mechanical ventilation in an intensive care unit (ICU), until the lungs recover. In case of further deterioration, ECMO (Extracorporeal membrane oxygenation) systems can control gas exchanges for weeks. This can be complicated with other causes such as shock and multiple organ failure. The biochemical profile of non-survivors shows low lymphocyte counts, high C-reactive protein and D-dimer levels, which may not succinctly provide the actual process of death. Due to the stretched health care systems, it becomes difficult to interpret the cause of death as specifically due to COVID-19 or as a result of treatment limitations. In addition, we need to factor the age-group of many hospitalized patients who are elderly and frail where-in COVID-19 infection could be an epiphenomenon [17]. Many patients in middle-care units will end up receiving non-invasive ventilation and vasopressor support, for whom the chances of survival might be assessed as low. Apart from the viral infection, we need to assess the patient's underlying condition while determining the cause of death. Lack of resources such as medical facilities, beds, personnel or equipment could compound the situation.

The preparedness plan for tackling COVID-19 as evidenced from UK [3], comprises of four phases: containment, delay, mitigation and research. Containment (prevention) comprises of hand washing, detection, isolation, care of infected people, contact tracing and screening of contacts. Delay includes social distancing measures such as school closure, cancellation of gatherings and avoiding non-essential use of public transport. Mitigation (control) for established infection was implemented in China, Italy, Iran, and South Korea during AprilMay 20, to enable optimum patient care, maintenance of essential hospital services and provision of community support for infected individuals [3]. Such mitigation plans should be tailored to the local demographics, as was evident in Italy which shows a high rate of severe or fatal cases due to the older population in its affected regions [3].

The National lockdown in India from $25^{\text {th }}$ March 20 till $31^{\text {st }}$ May 20 will enable reducing the rate of COVID-19 transmission. In countries such as Italy, Spain, USA (especially New York) social distancing was not maintained during the initial stages of epidemic which lead to the spread of the disease in an expe- 
ditious manner. During the early stages of infection in the first fortnight of March 20, the Indian Government screened incoming travellers for symptoms of fever at airports and seaports. It advised quarantine at Government facilities for those in-bound from COVID-19 epicenters (China, Italy, South Korea, Iran, Japan) and home quarantine for others. However, the advisory should have insisted quarantine at state run facility for passengers in-bound from new hotspots as well.

$\mathrm{R}_{\mathrm{t}}$, the real-time effective reproductive number depicts the number of people a COVID-19 patient can infect on average at a given time " $t$ ". This is an effective version of the basic $R_{0}$, which is the virus actual transmission rate at " $t$ ". The Institute of Mathematical Sciences at Chennai [24], estimates that $R_{t}$ had declined to 1.55 during the second week of April 20 indicating a slight flattening of the curve. Post-relaxation of the lockdown in India from $1^{\text {st }}$ June 20 , there is a risk of $\mathrm{R}_{\mathrm{t}}$ increasing or the doubling rate of infection decreasing. Overdispersion means that a minority of infected individuals are responsible for an unexpectedly high percentage of transmission, depending on the pattern of social contact. Simulation models need to account for the heterogeneity of the Indian population including the urban-rural disparity, requirement of the healthcare personnel, PPE kits for them, availability of medical infrastructure including ventilators.

High income countries like US, Italy and France have struggled to contain this epidemic, and other countries like Singapore, South Korea are finding it hard to mitigate the initial gains in containment. This reflects the highly contagious nature of the SARS CoV-2 virus. Communities need to actively participate in social distancing measures for atleast one year, before which we can relax on the engagement. Civic responsibility is important during the protracted nature of the response. Over the course of one year by which time a vaccine will be hopefully developed, the target for doubling time (doubling of the total number of cases) should be 45 days and for $R_{t}$ it is $<1.12$. The ideal $R_{0}$ to target is $<1$, which is an indicator of stoppage of transmission. The Kerala model of reverse isolation post-lock down, which focus on containing elderly and those with co-morbidities will buy us more time [25].

As on the third week of October 20, US is reporting a second wave of the pandemic. Dr.Nuzzo J. from John's Hopkins University opines that the wave is a description of the visible peak in the number of cases or deaths. It is difficult to count the number of waves until the pandemic is over. The COVID-19 pandemic may not pan out like the 1918 influenza pandemic which had three peaks in deaths. More than the virus, the contribution to the rise and fall of the epidemic depends on the behaviour of the community. Since incidence is driven by inaction, targeted public health measures need to be implemented to stop the transmission of corona virus. This includes testing, case isolation, contact tracing and infection prevention practices like physical distance and masks.

It is imperative to ensure healthcare workers are provided protective gear (N95 masks, goggles, protective gowns) similar for Group A infections such as 
Cholera and Plague [26]. Survival rate of COVID-19 patients on ventilator care is low, varying from $14 \%$ to $34 \%$ [27].

\section{Conclusions}

Contact tracing is an important tool to break the chain of transmission of infectious disease. While addressing the current epidemic in India, we need to build a pool of trained contract tracers as part of the Integrated Disease surveillance system. Such activities supported by good quality, accessible testing will play a critical role in preventing the present and second wave of the COVID-19 epidemic. Training such tracers is more practical when compared with providers being trained in intensive care. For sick cases, the ventilator facilities and its functionalities are located in the urban areas, which is a detriment for continued response efforts. The crucial performance indicators in the Indian context include the role of tests (screening vs diagnosis), daily capacity for testing and turnaround time for lab results.

Scoring of Prevalence and CFR along with RR will highlight the high risk areas and enable the development of point-of-care tools. When comparing the COVID-19 CFR and mortality rates between different countries and regions, we need to ensure transparency in the reporting policies of laboratory tests, clarity of the denominator measure used to calculate CFR, and appropriate retrieval of demographics such as age, sex and clinical co-morbid status of affected patients.

For improving the chances of survival following an infection, it is vital to access medical care at an early stage. Unique strategies need to be employed for high-risk groups such as elderly and those with co-morbidities such as hypertension, diabetes and cancer. Public health communication about the epidemic needs to be coherent and scientific. Travel restrictions imposed by $\sim 100$ countries [28] during the period April-May 20 (2 months) need to consider the implications for trade, supply chains for food and resources including medical equipment.

\section{Key Points}

Question: Estimating the COVID-19 case fatality rate (CFR), recovery rate (RR) and prevalence rate (PR) of the infection across countries.

Findings: This record based retrospective cohort study was conducted to compute the COVID-19 morbidity and case fatality rates across countries. Although variations exist in computing the case fatality rate across countries, it remains the best tool to express the fatality of the disease.

Meaning: Measures such as PR, RR and CFR will highlight the high risk areas, and enable the development of point-of-care tools.

\section{Conflicts of Interest}

The authors declare no conflicts of interest regarding the publication of this paper. 


\section{References}

[1] https://www.who.int/emergencies/diseases/novel-coronavirus-2019/events-as-theyhappen

[2] https://www.who.int/docs/default-source/coronaviruse/situation-reports/20200505sitrep-106.pdf?sfvrsn=47090f63 2

[3] Editorial (2020) COVID-19: Delay, Mitigate, and Communicate. Lancet Respiratory Medicine, 8, 321. https://doi.org/10.1016/S2213-2600(20)30128-4

[4] https://www.statista.com/study/71007/the-coronavirus-disease-covid-19-outbreak/

[5] Michael, M.W. (2013) Estimating Disease Prevalence and Incidence Using Administrative Data: Some Assembly Required. Journal of Rheumatology, 40, 1241-1243. https://doi.org/10.3899/jrheum.130675

[6] Kristiansen, I.S., Burger, E.A. and De Blasio, B.F. (2020) Covid-19: Simulation Models for Epidemics. Tidsskrift for Den norske legeforening, 4. https://doi.org/10.4045/tidsskr.20.0225

[7] Burki, T.K. (2020) Coronavirus in China. Lancet Respiratory Medicine, 8, 238. https://doi.org/10.1016/S2213-2600(20)30056-4

[8] Fang, L., Karakiulakis, G. and Roth, M. (2020) Are Patients with Hypertension and Diabetes Mellitus at Increased Risk for COVID-19 Infection? Lancet Respiratory Medicine, 8, e21. https://doi.org/10.1016/S2213-2600(20)30116-8

[9] Cai, H. (2020) Sex Difference and Smoking Predisposition in Patients with COVID19. Lancet Respiratory Medicine, 8, e20. https://doi.org/10.1016/S2213-2600(20)30117-X

[10] https://www.worldometers.info/coronavirus/

[11] https://www.physiopedia.com/Epidemiology, Prevalence and Incidence

[12] Dong, E., Du, H. and Gardner, L. (2020) An Interactive Web-Based Dashboard to Track COVID-19 in Real Time. The Lancet Infectious Diseases, 20, 533-534. https://doi.org/10.1016/S1473-3099(20)30120-1

[13] Porta, M. (2008) A Dictionary of Epidemiology. 5th Edition, Oxford University Press, Oxford.

[14] Spychalski, P., Blazynska, A.S. and Kobiela, J. (2020) Estimating Case Fatality Rates of COVID-19. The Lancet Infectious Diseases, 20, 774-775. https://doi.org/10.1016/S1473-3099(20)30246-2

[15] Khafaie, M.A. and Rahim, F. (2020) Cross-Country Comparison of Case Fatality Rates of COVID-19/SARS-COV-2. Osong Public Health and Research Perspectives, 11, 74-80. https://doi.org/10.24171/j.phrp.2020.11.2.03

[16] https://jamanetwork.com/journals/jama/fullarticle/2763667

[17] Vincent, J.L. and Taccone, F.S. (2020) Understanding Pathways to Death in Patients with COVID-19. Lancet Respiratory Medicine, 8, 430-432. https://doi.org/10.1016/S2213-2600(20)30165-X

[18] Onder, G., Rezza, G. and Brusaferro, S. (2020) Case-Fatality Rate and Characteristics of Patients Dying in Relation to COVID-19 in Italy. Journal of American Medical Association. https://doi.org/10.1001/jama.2020.4683

[19] Basu, D. (2020) India's COVID-19 Testing Conundrum: Why the Govt and Critics Are Both Right.

https://science.thewire.in/health/india-covid-19-testing-contradiction-rate/

[20] https://www.britannica.com/science/case-fatality-rate

[21] Shankar, M. and Bhan, A. (2020) India Needs to Ramp up COVID-19 Testing, 
Learn from South Korea \& Avoid US’ Mistakes. https://theprint.in/health

[22] Gupta, N., et al. (2020) Severe Acute Respiratory Illness Surveillance for Corona Virus Disease 2019. India, 151, 236-240.

[23] Peravali, C.J. (2020) Community Transmission Is Here, What Should We Do? https://newindianexpress.com/states/tamil-nadu/2020/may/07

[24] The Institute of Mathematical Sciences (2020) https://imsc.res.in/computational biology

[25] Shankar, M. and Bhan, A. (2020) COVID-19 Fight Is a Test Match, Not a T20. Here's What India Needs to Do to Win. https://theprint.in/science

[26] Chang, D., et al. (2020) Protecting Health-Care Workers from Subclinical Cornonavirus Infection. Lancet Respiratory Medicine, 8, e13. https://doi.org/10.1016/S2213-2600(20)30066-7

[27] Shankar, M. and Bhan, A. (2020) More than Ventilators, India Needs Thousands of Coronavirus Contact-Tracers. https://theprint.in/india

[28] https://www.thehindubusinessline.com/economy/covid-19-impact-global-economy -could-shrink-by-almost-1-per-cent-in-2020-say-un/article31233688.ece 